\title{
Venous syndromes and pulmonary embolism in systemic lupus erythematosus
}

\author{
DAFNA D. GLADMAN AND MURRAY B. UROWITZ \\ From the University of Toronto Rheumatic Diseases Unit, the Wellesley Hospital, Toronto, Ontario, and the \\ Women's College Hospital, Toronto, Ontario
}

SUMMARY Deep vein thrombophlebitis (DVT) and pulmonary emboli (PE) have been uncommonly reported manifestations of systemic lupus erythematosus (SLE). This may be partly due to their being masked by other more familiar lesions of the lungs and extremities in SLE. We have identified 17 patients with SLE from a population of 180 being followed up prospectively who had 21 attacks of DVT and/or PE. Of the total of 21 episodes the SLE was considered to be active in 14, inactive in 6 , and variable in a patient with recurring phlebitis. The incidence of hyperlipidaemia, smoking history, and use of birth control medication or corticosteroids was no higher in these patients. These clinical findings thus constitute additional features of SLE occurring in about $9 \%$ of patients and may be of significance for morbidity and mortality.

Venous syndromes and pulmonary emboli (PE) have not been commonly reported manifestations of SLE. This may in part be due to the masking of the features of these clinical conditions by other more familiar lesions of the lungs and extremities in this disease. In the course of a prospective study of 180 patients with SLE we identified 17 patients who had 21 attacks of a venous syndrome and/or PE. The purpose of this study was to analyse the incidence of these clinical syndromes and their relation to the disease activity of SLE and to assess whether they segregated a distinct subset of patients with SLE.

\section{Materials and methods}

Between July 1970 and July 1977, 180 patients have been followed up prospectively at the Lupus Clinic at the Wellesley Hospital. The standard protocol included both clinical and laboratory evaluation, the latter consisting of complete blood counts, Westergren sedimentation rate, Coombs test, coagulation screen, liver and renal function tests, and serum cholesterol and triglyceride levels. Serological tests included Venereal Disease Research Laboratories (VDRL), latex fixation test for rheumatoid factor, LE cell preparation, antinuclear factor (immunofluorescent technique with rat liver or mouse kidney slices as substrate), DNA binding (Farr

Accepted for publication 29 June 1979

Correspondence to Dr M. B. Urowitz, Suite 651A, The Wellesley Hospital, 160 Wellesley Street East, Toronto, Ontario, M4Y 1J3, Canada. assay with $\mathrm{I}^{125}$ ), total haemolytic complement (CH50) by the method of Kabat and Mayer, ${ }^{1}$ and levels of the third component of complement (C3) (with immunodiffusion plates, Kent Laboratories).

Venous syndromes presented as either of 2 clinical conditions, thrombophlebitis or phlebothrombosis. Thrombophlebitis was diagnosed by the presence of pain and/or tenderness in a deep vein distribution with swelling of the leg. When possible, venograms were performed to confirm the diagnosis. Phlebothrombosis was distinguished from thrombophlebitis by the absence of pain and tenderness and was diagnosed by the presence of swelling alone or by means of a positive venogram in the absence of any clinical manifestations.

Pulmonary emboli were diagnosed on the basis of an acute episode of shortness of breath associated with hypoxia (not corrected by $\mathrm{O}_{2}$ ), electrocardiographic findings of right heart strain and/or $\mathrm{Tc}^{99}$ perfusion lung scans showing perfusion defects in contrast to a normal chest $x$-ray. The presence of pulmonary infarction, as manifested by pleuritic pain, haemoptysis, a pleural rub, and chest $x$-ray showing triangular shaped infiltrate was considered evidence for a preceding PE as well.

Patients were considered to have active SLE if they had 2 or more of the following clinical symptoms or signs: alopecia, butterfly rash, mucous membrane ulcerations, serositis, arthritis, proteinuria, or a renal biopsy showing active nephritis, neuropsychiatric symptoms, myositis or peripheral vasculitis, and/or 3 or more of the following serological abnormalities: 
elevated DNA binding, leucopenia, biological false positive test for syphilis, positive Coombs test, hypergammaglobulineamia, and decreased levels of complement (either $\mathrm{CH} 50$ or $\mathrm{C} 3$ ).

\section{Results}

Seventeen patients with SLE had 21 attacks of a venous syndrome and/or PE. There were 16 females and 1 male, with a mean age of 36.5 years (range 20-53). All but 3 patients fulfilled 4 or more of the ARA criteria for the classification of SLE. ${ }^{2}$ Although the remaining 3 patients fulfilled only 3 criteria each, they had other clinical and laboratory features of SLE (Table 1). Thus, patient 2 had pleurisy, Raynaud's disease, and arthritis, but in addition had proteinuria of $675 \mathrm{mg}$ per 24 hours, a positive ANF and low $\mathrm{CH} 50$. Patient 8 had pleurisy, arthritis, and a biological false positive test for syphilis, and as well as proteinuria of $750 \mathrm{mg}$ per 24 hours, an abnormal electroencephalograph, raised DNA binding, and low serum complement (both $\mathrm{CH} 50$ and $\mathrm{C} 3$ ). Patient 14 had pleurisy, arthritis, and a positive LE test as well as a peripheral neuropathy, raised DNA binding, and low serum complement and hypergammaglobulinaemia. The mean number of ARA criteria in this group of 17 patients was 7.

Of the 21 episodes (Table 2), 5 consisted of a venous syndrome alone, 11 presented a venous syndrome with associated proved $\mathrm{PE}$, and 5 episodes of PE alone. In the latter 5, venous disease was not conclusively ruled out, as 2 had only a unilateral
Table 2 Diagnosis of venous syndromes and pulmonary emboli in 17 patients with SLE

\begin{tabular}{|c|c|c|c|c|}
\hline \multicolumn{3}{|c|}{ Venous syndromes } & \multicolumn{2}{|c|}{ Pulmonary emboli } \\
\hline & Clinical & Venogram & Clinical & Lung scan \\
\hline \multirow[t]{2}{*}{1} & + & ND & + & ND \\
\hline & + & ND & + & ND \\
\hline \multirow[t]{2}{*}{2} & + & ND & + & + \\
\hline & + & ND & + & + \\
\hline 3 & + & ND & - & ND \\
\hline 4 & + & ND & + & + \\
\hline 5 & - & + & + & + \\
\hline 6 & + & ND & - & ND \\
\hline 7 & + & + & - & ND \\
\hline 8 & + & - & - & - \\
\hline 9 & - & + & + & + \\
\hline 10 & - & + & + & + \\
\hline \multirow[t]{2}{*}{11} & + & ND & + & + \\
\hline & - & ND & + & + \\
\hline 12 & - & - (Unilateral) & + & + \\
\hline 13 & -- & ND & + & + \\
\hline 14 & - & - (Unilateral) & + & + \\
\hline \multirow{2}{*}{15} & + & ND & - & - \\
\hline & + & ND & + & + \\
\hline 16 & - & + & + & + \\
\hline 17 & - & - & + & + \\
\hline
\end{tabular}

venogram and 3 had no venograms performed at all. The 16 episodes of venous disease included typical thrombophlebitis in 12 and phlebothrombosis suspected clinically and confirmed with venography in 4 . One patient (9) had an inferior vena cava thrombosis extending into the renal veins. Thirteen patients had a single attack, 3 had 2 each, and an additional patient (15) had 2 attacks, the second one recurring chronically whenever anticoagulation was stopped.

Table 1 Manifestations of disease activity at time of venous syndrome and/or pulmonary emboli in 17 patients with SLE

\begin{tabular}{|c|c|c|c|c|c|c|c|c|c|c|c|c|c|c|c|c|}
\hline Case & $\begin{array}{l}\text { Dis. } \\
\text { durn* }\end{array}$ & $\begin{array}{l}\text { Alo- } \\
\text { pecia }\end{array}$ & $\begin{array}{l}\text { Malar } \\
\text { rash }\end{array}$ & $\begin{array}{l}\text { MM } \\
\text { ulcers }\end{array}$ & $\begin{array}{l}\text { Sero- } \\
\text { sitis }\end{array}$ & $\begin{array}{l}\text { Arth- } \\
\text { ritis }\end{array}$ & Renal & $N P^{* *}$ & $\begin{array}{l}\text { Myo- } \\
\text { sitis }\end{array}$ & $\begin{array}{l}\text { Vascu- } \\
\text { litis }\end{array}$ & $\begin{array}{l}\text { Decr. } \\
W B C\end{array}$ & $B F P$ & Coombs & $\begin{array}{l}\text { Incr. } \\
\text { Yglob. }\end{array}$ & $\begin{array}{l}D N A \\
A b\end{array}$ & $\begin{array}{l}\text { Decr. } \\
C\end{array}$ \\
\hline \multirow[t]{2}{*}{1} & 14 & - & + & - & + & + & - & + & - & + & + & - & - & + & ND & ND \\
\hline & 27 & - & - & - & - & + & - & + & - & - & - & - & - & + & ND & ND \\
\hline \multirow[t]{2}{*}{2} & 0 & - & + & - & + & + & + & - & - & - & - & - & - & - & - & - \\
\hline & 1 & - & - & - & - & - & + & - & - & - & - & - & - & - & - & - \\
\hline 3 & 6 & + & + & + & + & + & - & + & - & - & - & - & - & - & - & + \\
\hline 4 & 7 & + & + & - & + & + & - & + & - & + & - & - & - & - & - & - \\
\hline 5 & 4 & + & - & + & - & + & + & + & + & + & - & - & - & - & - & - \\
\hline 6 & 0 & - & - & - & - & + & - & - & - & - & + & + & - & - & + & + \\
\hline 7 & 15 & - & + & - & - & + & - & - & - & - & + & - & - & - & + & + \\
\hline 8 & 0 & - & - & - & + & + & + & + & - & - & - & + & - & + & + & + \\
\hline 9 & 5 & - & - & + & - & + & + & - & + & - & + & - & - & - & - & - \\
\hline 10 & 2 & - & + & + & - & + & + & + & + & + & - & - & - & - & - & - \\
\hline \multirow[t]{2}{*}{11} & 1 & + & - & + & - & + & - & + & - & - & + & - & - & - & - & - \\
\hline & 6 & - & - & - & - & + & $\rightarrow$ & - & - & - & - & - & - & - & - & - \\
\hline 12 & $4 \frac{1}{2}$ & - & - & - & - & - & - & + & - & - & - & - & - & - & - & - \\
\hline 13 & 1 & + & + & - & - & + & - & - & - & - & + & - & - & - & - & + \\
\hline 14 & 10 & - & - & - & - & + & - & - & - & - & - & - & - & - & + & - \\
\hline \multirow[t]{2}{*}{15} & $1 \frac{1}{2}$ & + & + & + & - & + & + & - & - & - & - & - & - & - & ND & ND \\
\hline & $14 \frac{1}{2}$ & & Variable & course & Recu & rent $\mathrm{ph}$ & bitis & & & & & & & & & \\
\hline 16 & $12^{2}$ & - & - & - & - & - & - & - & - & + & - & - & - & - & - & - \\
\hline 17 & 11 & + & + & - & - & - & - & + & + & + & - & - & - & - & - & - \\
\hline
\end{tabular}

*Disease duration (in years). ${ }^{* *}$ Neuropsychiatric

$M M=$ mucous membrane. $\mathbf{B F P}=$ biological false positive test for syphilis. $A b=$ antibody. $C=$ complement. $N D=$ not done. Incr. $=$ increased Decr. $=$ decreased. 
All 5 patients with a venous syndrome alone had active SLE at the time of the venous episode, this being part of the initial presenting symptom complex in 3 patients and associated with a flare of SLE in 2 other untreated patients. Seven of 11 patients presenting with both a venous syndrome and PE were considered to have active disease, and the disease was variably active in the patient with recurring phlebitis. Only 2 of 5 patients with PE alone had active SLE at the time of the embolism.

All episodes of DVT or PE were treated with anticoagulation. Six episodes were also treated with increased steroid dose.

Of the 17 patients 2 were taking salicylates, 4 chloroquine, 13 prednisone, and 3 azathioprine at the time of venous syndrome. Only 1 patient had taken birth control medication for 2 years up to the time of developing the venous syndrome. Three others had taken birth control pills a number of years before the episode. Eight of the 17 patients smoked. Cholesterol and triglyceride estimations were available for 16 patients. In 2 both triglycerides and cholesterol were raised at the time of the episode. One other patient had hyperlipidaemia during the course of her illness.

Renal biopsies were performed in 5 patients and renal pathology was obtained at necropsy in another patient. Only 1 patient (9) had membranous nephropathy; she also had renal vein thrombosis. Two patients had focal proliferative glomerulonephritis, one had mesangial proliferation, and the fifth had mesangial sclerosis. Renal tissue from patient 11 showed immune deposits in a mesangial distribution at necropsy.

When compared to the total group of 180 patients these patients did not differ significantly from those without venous syndromes with reference to clinical features and serological variables. Fewer patients in the group with venous syndromes were taking steroids $(70.5 \%$ versus $92.6 \%, \mathrm{P}<0.01)$, and salicylates $(11 \cdot 8 \%$ versus $42 \cdot 3 \%, \mathrm{P}<0 \cdot 05)$. There was no statistical difference in the incidence of hyperlipidaemia, smoking history, or of the use of birth control medications between the 2 groups.

All patients were ambulatory at presentation with DVT or PE.

Five patients ( $29 \%)$ of the group of 17 with venous syndrome and/or PE have died after mean duration of disease of 8.6 years. In all 5 patients pulmonary emboli were considered to have contributed to their death.

\section{Discussion}

Venous syndromes have not been frequently reported in SLE. In Dubois's series of 520 patients $^{3}$ thrombophlebitis occurred in 24 or $4.6 \%$ and was the presenting symptoms in $24(0.4 \%)$. Armaz-Cruz and associates ${ }^{4}$ found thrombophlebitis in 13 of 108 patients with SLE. Moore and Lutz ${ }^{5}$ found 3 instances of thrombophlebitis among 21 cases of SLE. Alarcon-Segovia and Osmundson ${ }^{6}$ described unexplained often recurrent and superficial thrombophlebitis in 5 patients. More recently Peck et al. ${ }^{7}$ described thrombophlebitis in 14 of 114 patients with active SLE. Other large series have not discussed this entity.

We have described a group of 17 patients who had 21 attacks of a venous syndrome and/or PE. Of the 21 episodes 16 consisted of a venous syndrome with or without PE. In these 16 episodes the SLE was considered to be active in 12 cases. On the other hand of 5 episodes of PE without an accompanying venous syndrome the SLE was active in only 2 . It is therefore likely that venous syndromes are a feature of SLE and that pulmonary emboli result as a complication of it. They might cause both diagnostic and therapeutic confusion, as the symptoms of PE may mimic those of lung lesions due to SLE. This confusion resulted in 6 of the episodes being treated with both corticosteroids and anticoagulants.

Renal vein thrombosis has been reported in 11 patients with SLE. ${ }^{8-11}$ In 5 of these patients renal biopsies showed membranous lesions. More recently a case showing renal vein thrombosis and nephrotic syndrome with focal glomerulonephritis was reported. ${ }^{11}$ In our series only 1 patient had renal vein thrombosis and nephrotic syndrome. Her renal biopsy showed a membranous lesion. Of the additional 5 patients whose renal tissue was available 2 had focal glomerulonephritis, one with PE alone and the other with a recurrent venous syndrome. Two patients had mesangial involvement, both with a venous syndrome and PE. One patient with PE and a venous syndrome had mesangial sclerosis. None of these patients had any evidence of nephrotic syndrome or renal vein thrombosis. Three of our patients had a circulating anticoagulant detected at the time of the attack. Although the appearance of thromboembolism despite the presence of a circulating anticoagulant has been previously reported, ${ }^{12}$ it remains to be explained. In addition, in 3 patients partial thromboplastin times were found to be lower than in controls at the time of venous syndromes and/or PE. It is possible that in these patients a hypercoagulable state was present. However, specific testing for antithrombin deficiency was not carried out.

These 17 patients did not differ in frequency of hyperlipidaemia, smoking, or intake of birth control medications from the remainder of our group 
of 163 patients with SLE who did not have such episodes. Fewer patients were taking steroids and acetylsalicylic acid at the time of the episode.

There were no other distinguishing clinical features or laboratory and serological variables in this group of patients. Thus the presence of venous syndrome with or without PE did not preselect a specific subset of patients. These clinical findings therefore constitute additional features of SLE or their complications, occurring in about $9 \%$ of patients, which may be of significance for morbidity and mortality.

Supported by a grant from the Canadian Arthritis Society no. 1-144-(70).

\section{References}

1 Kabat E A, Mayer M M. Experimental Immunochemistry, 2nd ed. Springfield: Thomas, 1964; 149.

2 Cohen A S, Reynolds W E, Franklin E C, Kulka J P, Ropes M W, Shulman L E, Wallace S L E. Preliminary criteria for the diagnosis of systemic lupus erythematosus. Bull Rheum Dis 1971; 21 : 643-648.

3 Dubois E L. Lupus Erythematosus. 2nd edition, Los
Angeles: University of Southern California Press, 1974; 285.

4 Armaz-Cruz R, Harnecker J, Ducach G, Jalil J, Gonzalez F. Clinical diagnosis of systemic lupus erythematosus, Am J Med 1958; 25: 409-419.

5 Moore J E, Lutz W B. The natural history of systemic lupus erythematosus: an approach to its study through chronic biologic false positive reactors. J Chronic Dis 1955; 1 : 297-316.

6 Alarcon-Segovia D, Osmundson P J. Peripheral vascular syndromes associated with systemic lupus erythematosus. Ann Intern Med 1965; 62: 907-919.

7 Peck B, Hoffman G S, Franck W A. Thrombophlebitis in systemic lupus erythematosus. JAMA 1978; 240: 17281730.

8 Hamilton C R Jr., Tumulty P A. Thrombosis of renal veins and inferior vena cava complicating lupus nephritis. JAMA 1968; 206: 2315-2317.

- Appel G B, Williams G S, Meltzer, J I, Pirani C I. Renal vein thrombosis, nephrotic syndrome and systemic lupus erythematosus. Ann Intern Med 1976; 85: 310-317.

10 Kahn M A, Ricanti E S, Park M J C. Lupus nephritis and renal vein thrombosis. Ann Intern Med 1977; 86: 114.

11 Millett V G, Usera G, Alcazar De La Ossa J M, Ruilope L M, Ortuno M T, Rodicio J L. Renal vein thrombosis, nephrotic syndrome, and focal lupus glomerulonephritis. Br Med J 1978; 1: 24-25.

12 Bowie E J W, Thompson J H, Pacuzzi C A, Owen C A. Thrombosis in systemic lupus erythematosus despite circulating anticoagulants. J Lab Clin Med 1963; 62: 416-430. 